\title{
Digital Technology and Mobile Applications Impact on Zika and Ebola Epidemics Data Sharing and Emergency Response
}

Tambo $E^{1,2 *}$, Kazienga $A^{3}$, Talla $\mathbf{M}^{1}$, Chengho $\mathrm{CF}^{4}$ and Fotsing $\mathrm{C}^{1}$

${ }^{1}$ Africa Intelligence and Surveillance, Communication and Response (Africa DISCoR) Institute, Yaoundé, Cameroon

${ }^{2}$ Higher Institute of Health Sciences, Université des Montagnes, Bangangté, Cameroon

${ }^{3}$ Department of eHealth, Rome Business School, Rome, Italy

${ }^{4}$ Department of Health and Life Sciences, University of Coventry, Leicester, UK

\begin{abstract}
Increasing diversified world, era of international power diffusion and regionalisation as the world muddles through travel and trade to climate change requires promoting a more cohesive global regime to ameliorate the deficiencies in local and global 2013-2015 and 2015-2016 Ebola and Zika virus epidemics public health emergency of international concern respectively. Zika epidemics devastating and complex complications exposed the flaws in the global surveillance architecture to deal with cross-border health pandemics prevention and containment. This paper examines trade-off between technology-based data access and dissemination, Zika virus (ZIKV) epidemics complications and digital implications in care delivery solutions in pre-, during and post epidemics response and rebuilding. Our findings showed that IT-based health informatics and mobile applications are evolving and minimum global standards to open access and sharing of relevant epidemics data and information on risk communication. Public awareness and alertness, health promotion and education, counselling and guidelines on integrated syndrome surveillance and response were the most common goals and objectives during viral epidemics reduce and avert further transmission. The uses in healthcare services delivery, management, and planning was also documented and have played a critical role in raising awareness EVD and ZIKV travel restriction and delay pregnancy to women at reproductive age, effective use of personal protective equipment and cultural practices against EVD and ZIKV infections spread. Importantly, IT-based enhanced frontline improved collaborative data sharing and communication, coordinated response and recovery. The efficiency of IT-based data and information sharing and communication practices is of critical benefits for evidence informed early warning, social mobilization, advocacy, monitoring and evaluation capabilities. Mobile-based applications innovations during Zika and Ebola epidemics were very crucial for better evidence-based local and global preparedness and solutions to prevent and control epidemics impacts, promote shared benefits and economic growth.
\end{abstract}

Keywords: Digital technology; Social media; Zika; Ebola; Epidemics; Response; Implications

\section{Introduction}

The global community is confronting another damaging health epidemic. The Zika virus has spread more widely than the recent Ebola epidemic. The deadly impact of Ebola was mostly confined to three small, poor countries in West Africa and as at early 2016 was largely under control [1]. The 2014 Ebola virus disease epidemic in West Africa is the largest and most complex outbreak since the virus was first discovered in 1976. In contrast, the Zika virus threatens over 2 billion people globally, with over 4 million cases projected for the Americas alone. Zika, like yellow fever, the Chikungunya virus, and dengue fever, is primarily spread by Aedes aegypti mosquitoes living with humans all over the tropical world. The virus and viral diseases can spread constitutes a significant global health and economic security risk there are no licensed Ebola vaccines. However, treatment for specific symptoms and early supportive care rehydration improves chances of survival. The World Bank Group estimates that the short- and long-term economic impact for Latin American and Caribbean countries of Zika will be a US $\$ 3.5$ billion loss to Gross Domestic Products (GDP), with tourism-dependent countries particularly affected [2]. The Caribbean Tourism Organization estimates that a $2-4 \%$ decline in tourism would have a minimum adverse impact of \$200-400 million [3].

There is a ticking time bomb in national health systems that no government is set up to deal with and to assist national and international efforts to control the spread of the disease, the largest risks. The global health security emerge from threats and epidemics and the healthcare costs rising faster than the growth in GDP that is needed to fix the health governance gaps that surround the WHO; support the International
Health Regulations (IHR), 2005 and integrate antimicrobial resistance actions into national development plans [4]. Syndrome surveillance has been a core aspect of the meaningful use standards enforced by the Centres for Medicare and Medicaid Services, and electronic health records adoption is on the rise by as much as $55 \%$ and data remains unable to be utilized effectively for public health benefits $[3,4]$

Similarly, the early-2000s SARS epidemic is a good illustrator of information as one of the most critical tools in addressing any type of public health crisis. SARS coordinated multi-disciplinary response organised by the World Health Organization (WHO), working with country offices and with support from the Global Outbreak Alert and Response Network, yet SARS still had an estimated $\$ 50$ billion impact [4]. SARS Cases spread like wildfire with more than 8,000 people becoming infected globally over a three-year time frame. That number may have been substantially lower if information about new cases had been monitored and shared to get an accurate picture of the prevalence and spread of the disease. More recently, Ebola case in

*Corresponding author: Ernest Tambo, Higher Institute of Health Sciences Université des Montagnes, Bangangté, Cameroon, Tel: +237-33-02-51; E-mail: tambo0711@gmail.com

Received March 07, 2017; Accepted March 22, 2017; Published April 2 , 2017

Citation: Tambo E, Kazienga A, Talla M, Chengho CF, Fotsing C (2017) Digital Technology and Mobile Applications Impact on Zika and Ebola Epidemics Data Sharing and Emergency Response. J Health Med Informat 8: 254. doi: 10.4172/2157-7420.1000254

Copyright: (c) 2017 Tambo E, et al. This is an open-access article distributed unde the terms of the Creative Commons Attribution License, which permits unrestricted use, distribution, and reproduction in any medium, provided the original author and source are credited. 
Texas, US illustrated a public health worker as unprepared to act on access to a hospital's electronic health records containing information about the patient's travels that could have resulted in immediate action, while simultaneously maintaining the privacy of pertinent patient data. Likewise, the most severely affected countries by widespread Ebola virus transmission include Guinea, Liberia, and Sierra Leone. These countries currently have very weak health systems with limited resources to effectively treat sick patients, and curb the spread as a Public Health Emergency of International Concern under the International Health Regulations, 2005. The rapid spread of the virus has triggered a response from organizations, politicians, researchers, healthcare workers, and volunteers worldwide in ensuring healthy lives and promoting wellbeing for future generations [5].

Information and communication Technologies (ICTs) ICTs help support effective outbreak surveillance and control strategies, including but not limited to, contact tracing, social mobilization, mapping, communication, monitoring, and response [4,5]. It also can assist national and international efforts to control the spread of the disease, have played, and continue to play a critical role in raising awareness about Ebola, prevent the spread of the disease, and support the role of frontline healthcare workers by providing better means to communicate simple, trustful and reliable instructions and information [6]. In such innovative approaches that connect biomedical and social sciences, that are community-based, and that use new technology that proactively forecast/anticipate, detect, and respond to current and emerging threats, while providing primary healthcare coverage for all. Full spectrum of promotion of national health systems prevention, treatment, and care services in an inclusive way that provides equal access and brings new opportunities and benefits to personalized medicine, technology and social practices to a globalised world $[6,7]$. However, digital innovations during and post-Zika and Ebola outbreak continue to be developed; unforeseen consequences should be tackled promptly [5,6]. Ethical, legal and medical issues associated Zika complications and use of compassionated serum treatment during Ebola or deployment of military forces in vector breeding sites ablation, care delivery and human protection have been reported and patient/survivors rights considerations that emerge from international Zika and Ebola response have also been documented in affected areas in West Africa Ebola, or Zika epidemics in Brazil, Cuba, The America and Colombia $[2,3,6,8]$. Nevertheless, limited attention has been given to ethical ICT access and use considerations during and post Zika and Ebola epidemics particularly leveraging on digital applications implications on future epidemics while rapid development and growth $[6,8]$.

Still, there is lack of uncovered a host of barriers and obstacles to effective use of information, including the complexity and usability of the software, the inability of the software to support certain unique public health reporting needs, the learning curve for public health workers, and the lack of standards for effective data exchange, guidance to effectively strategize about appropriate ICT-innovations investments and current Zika epidemics crisis incidents and forefront data and information sharing systems as front-line safety and protection of affected communities or vulnerable populations against emerging epidemics impact relies on seamless information sharing, global leadership commitment and investment $[9,10]$.

Mobilizing joint financial resources in building digital epidemics platform, preparedness and response to support essential public health program and strategies is crucial to combating these deathly emerging viruses. Moreover, in strengthening Aedes mosquito and great-apes control programs reductionist implementation and fast-tracking safe and efficacious Zika and Ebola more sensitive field or point of care diagnostic, safe and effective vaccine research and development $[2,11]$. Developing and implementing context specific awareness and education programs and activities to healthcare workers and providers, pregnant women and their family capacity and resilience capability. These are important in long term integrated programs sustainability and in improving our understanding of full epidemiology of reservoirs sources, mosquitoes transmission and spread, and laboratory testing; and supports better healthy living and wellbeing for low-income vulnerable populations mainly pregnant women in Zika and Ebolaaffected countries $[12,13]$.

There is much that we do not yet know about Zika and Ebola survivors long-term impacts and its relationship to disability and poor health outcomes that are being reported in affected areas $[1,3-5,13,14]$. Robust and sustained financial resources and leadership commitment are needed to investigate reservoirs, immune response profile and evolving risk factors of these outbreaks (animal, environment, human interface), and much needed for evidence-based, programmatic and effective mitigation actions to the best extent possible. But also, bolstering digital applications potential and opportunities in accelerating local, national and global capacity development and capabilities to prevent, detect and respond to emerging and future (Zika, Ebola, flu, SARS) viruses threats and outbreaks [15].

The paper assesses the social media and digital-based applications impact in emerging Zika and Ebola epidemics, and advocates the need to leverage on recent digital technology advances to inform emerging threat and epidemic preparedness and rapid response decision making policy and resilient interventions.

Access to and use of social media and digital-based applications on Zika and Ebola epidemics data and information dissemination.

Zika virus epidemics similar to West Africa Ebola outbreak scourge that led to 11,325 death out of 28,657 cases has emerged as contemporary emerging viral diseases of global public health importance requiring urgent partnership and resources mobilization to prevent, control and contain the horror [16]. Addressing the dreadful epidemics impact on health and economic requires innovative capabilities to support health systems and frontline workforce, in fostering continuous risk communication and awareness for timely decision making policies, readiness and rapid response interventions strategies improvements and frontline such as enhanced ICT-based and social media applications benefits $[2,7,17]$. Real time, comprehensive and reliable access to and advocacy for use of Zika virus epidemics data and information can be very timely in risk identification, magnitude of transmission and spread within and between populations, early community alertness and awareness, risk communication, prognosis and early warning, social mobilization and community engagement.

Zika and Ebola epidemics data and information sharing have been very useful to governments, frontline humanitarian agencies and other stakeholders in logistics, priorities setting, timely real time rescue or support system and contingency measures $[3,16]$. But also assist in mapping geographical spread and dynamics, education and training. IT-based quality control, monitoring and evaluation on the pattern and trend of instructions and guidelines impact and innovations, understanding of infection source (s) including Aedes mosquito bite, blood transfusion from infected blood products, unprotected sexual intercourse with infected person, Zika virus transmission dynamics and spread as well as coverage performance and effectiveness of preventive 
and treatment care delivery or effective response strategy in these recent epidemics through various IT applications $[6,18]$. For example Zika epidemics-related Twitter incidence showed that User-generated contents sites were preferred direct information channels rather than those of the government authorities including societal impact of the outbreak; government, public and private sector, and general public responses to the outbreak; pregnancy negative health consequences related to pregnant women and babies outcomes, microcephaly and neurological syndrome; transmission routes; and new case reports $[3,5,9,17]$. A recent published paper on Zika epidemics have shown that the public showed more concern about the complications or consequences it had for women and babies, whereas WHO and CDC increased Zika epidemics guidelines and precautionary measures for women at child bearing information, awareness and active education. Whereas, another study showed such approach that tends to be episodic and ephemeral rather than coherent, comprehensive and sustained by all stakeholders over time $[19,20]$. Public authority announcements can give the importance of trust and credibility for information acceptance using Google Trends. Time series data can reflect autocorrelation that makes observed relationships spurious, interpretations of results suggest that news coverage of public health authority announcements opens brief windows of information sharing, engagement, and searching that offer opportunities to address perceptions and provide preparation and vector control recommendations, but not generalize beyond the initial stages of Zika, complications, country or affected groups. Ebola and Zika epidemics behaviour and social media interactions tended to respond to news, intensity of the coverage, especially reactions health issues $[5,10,13,21]$.

Applications of social media, crowding and digital internetbased networks is crucial in mapping and early warning alert enables communities awareness and vigilance to handle alert instructions, preventive and management guidelines in future unexpected epidemics events. Such interactive and real time social mobilization, information via social media; SMS and internet-based information sharing enables individuals, patient groups or survivors and communities to understand epidemics and transmission dynamics, safety and precautionary measures to exposure, pathology and actions in control $[2,8-10,13,14]$. Proactive prevention and recovery approaches on from mobile applications information regarding these emerging outbreaks from humanitarian organizations, NGOs, healthcare workers, health professionals and communities are needed. In addition, the usefulness of mobile mapping, satellite images and drones were important in both epidemics in understanding the transmission dynamics or spread of vector or reservoir, contact tracing and tracking patients, population/animal (bats) movement and migration, thus leveraging on ICT advancements in real time and interactive data collection for evidence-driven decision making and early warning alert and resilience $[9,10,14,21]$. Furthermore, digital or mobile payment and finance transactions have been used in accepting donations from contributors and communication, in frontline healthcare workers, care providers and humanitarian logistics, tele-consulting and online tutorials, literacy and interactive feedbacks at all levels in West Africa Ebola and The Caribbean Zika epidemics affected areas including remote rural settings (Table 1).

Addressing ethical, social and medical viral epidemics response with ICT-based applications innovations. Increasing reliance on ICT-innovations and technologies and tools resulting access and use inequities have been documented mainly in remotes rural communities, low literacy and vulnerable populations as reported in Zika epidemics in rural settings in Brazil and Colombia to rural communities in West
Africa Ebola outbreaks [1,2]. Keeping the existing community and public informed about updates and mitigation wider reach through SMS and internet-based applications, social media engagement and participation individuals from remote rural communities. Moreover, to sharing objective and true journalism on burial practices on Ebola spread, monitoring closed circuit and other mass media surveillance data and information access and uptake against Zika and Ebola epidemics in high- and low risk zones and cross-borders entries ports, patients, individuals and collective displacement tracing, tracking and monitoring $[9,14,19,20]$.

Social media has also been the source of misinformation and stigma related to Zika and Ebola outbreaks. In October 2014, the University of Minnesota posted on Twitter that Ebola can be transmitted through the air. Several businesses have also used social media to advertise and sell products that they claim will provide consumers the same protection that is similar to what healthcare providers get in Zika and Ebola high risk zones [20,22-24]. For examples, sensitive and unethical images and images of suffering may also be displayed using social media. A YouTube video uploaded by the New York Times entitled "Ebola Virus Outbreak 2014 which has been viewed over 1.5 million times as of April 26, 2015 showed a young man dying from Ebola outside a healthcare facility in West Africa. At the end of the video, the father of the young man is shown walking away with cash in his hand, which has led commenters to believe the video is a dramatization or propaganda $[16,20,25]$. Therefore, social media misinformation, fear mongering and information abuse does not only lead to lack of trust in government and health officials, but may desensitize individuals to the severity of the virus. This can lead to people not taking proper safety and precautionary measures when travelling, and reaching out adequate guidelines and traveller update in emergency epidemics $[2,7,26,27]$. Such patient or uncertified images of suffering and display of Ebola patients in the media also raises questions regarding informed consent, dignity and privacy. While certain organizations have cautioned people against putting themselves in danger to collect footage, many media organizations do not emphasize the importance of ethical practice, patient dignity, seeking informed consent process and ethical clearance $[19,26]$.

For those who do not have access to mobile phones, such as the most poor or marginalized populations may be less likely to receive needed information or assistance. Furthermore, in cases where organizational or outreach decisions are based on electronic data as seen with Radar or Health Map-the most vulnerable persons in the community may be neglected and their needs not taken into account [28-30]. One of the biggest issues that emerged with the Ebola and Zika epidemic was the amount of inaccurate information (lack or little evidence) disseminated on social media that rose public fear mongering and mistrust, stigma and spams became common with open channels such as Facebook, Twitter and other social media networks [30]. This situation may diminish trust for healthcare workers and government. Important public health messages may become lost or overlooked with all the other information available. For example, in 2014, a rumour spread via Twitter that drinking copious amounts of salt water cures Ebola lead to two deaths in Nigeria $[8,11]$.

Using mobile applications as means of communication also raises ethical, medical and legal issues regarding personal data security, privacy and confidentiality as individuals become more connected via the internet and technology $[11,31,32]$. Digital applications access and uptake ethics and rights principles adherence via open channels (e.g. Tweeting, public image-sharing websites, public forums), and 


\begin{tabular}{|c|c|c|}
\hline Potential digital use in epidemics & Technology and tools applications & Implications and impact \\
\hline $\begin{array}{l}\text { Surveillance, tracing and tracking, mapping and Early } \\
\text { warning }\end{array}$ & $\begin{array}{l}\text { Social media, Digital Network Diagrams \& Maps, } \\
\text { crowding } \\
\text { Mobile mapping, CDRs, Satellite images, Drones }\end{array}$ & $\begin{array}{l}\text { Preparedness, instructions and guidelines, individuals } \\
\text { and communities mobilization, engagement ad } \\
\text { participation } \\
\text { Contact tracing, data-driven decision making frontline } \\
\text { action, early warning, population movement }\end{array}$ \\
\hline Social Mobilization, participation and resilience & Social Media, SMS \& IVSS & $\begin{array}{l}\text { Enables individuals and communities to } \\
\text { understand epidemic risk and initiation action for } \\
\text { recovery }\end{array}$ \\
\hline $\begin{array}{l}\text { Data and information access, reporting, sharing and } \\
\text { dissemination }\end{array}$ & Mobile Apps, Social Media, SMS & $\begin{array}{l}\text { Sharing information regarding the outbreak between } \\
\text { healthcare workers }\end{array}$ \\
\hline Advocacy and mitigation outreach to wider population & SMS, Mobile Apps, social media & $\begin{array}{l}\text { Mobilization, alert, instructions and advice } \\
\text { Communities engagement on disease and actions, } \\
\text { allows individuals in remote communities to shared } \\
\text { anecdotal and positive journalism }\end{array}$ \\
\hline $\begin{array}{l}\text { Risk communication and rebuilding trust and } \\
\text { confidence to the affected communities }\end{array}$ & Social media, Tele-consulting & $\begin{array}{l}\text { Patients can communicate with family and friends, } \\
\text { healthcare workers can communicate with patient }\end{array}$ \\
\hline $\begin{array}{l}\text { Reimbursements, incentivation payments and financial } \\
\text { management }\end{array}$ & SMS, Mobile apps & $\begin{array}{l}\text { Reimbursement, microcredit or insurance inquiries, } \\
\text { Paying healthcare workers, accepting donations from } \\
\text { contributors }\end{array}$ \\
\hline $\begin{array}{l}\text { Training care providers and field health workers } \\
\text { empowerment }\end{array}$ & SMS, mobile apps, webinars, and online tutorials & $\begin{array}{l}\text { Efficiently train new healthcare staff, keep existing staff } \\
\text { informed about updates }\end{array}$ \\
\hline Monitoring and evaluation & Closed Circuit social media, internet, thermal cameras & $\begin{array}{l}\text { Circuit social media, internet, TV, migration cameras } \\
\text { Surveillance of patients monitoring }\end{array}$ \\
\hline
\end{tabular}

Table 1: ICT applications and tools usefulness and impact on Zika and Ebola epidemics worldwide.

individuals posting sensitive information laws and regulations and guidelines should be strengthening in averting potential Ebola and Zika short and long-term threat and complications in future Ebola and Zika epidemics $[3,19,23]$.

Value of digital-based applications on epidemics and emergency humanitarian assistance and response. The identification and response to epidemics is increasingly influenced by digital and mobile-based technology. In turn, the development of new digital technologies and applications is influenced by how we share, respond to, and disseminate information during public health emergencies. There is little doubt that ICTs have positively impacted the ways in which decision-making policy and partnerships in resources mobilization, humanitarian aid workers, health workers, and people around the globe have addressed issues that arise with the Zika and Ebola epidemics [1,4,23]. Factors that were previously seen as barriers, such as information wider reach for all, real time health and epidemics literacy, online solutions and social mobilization and participation to the community have now being leveraged and optimized through advances digital technology access, acceptance and use. Previous studies have reported that the complexity level to prevent and respond to the Ebola and Zika virus epidemics events is due to the remoteness, underserved and culturally affected populations and weak health systems access and coverage inequities $[9,10,19,20]$.

However, ICTs have globally changed the way in which people communicate, and organizations like Radar (http://www.onourradar. org/) are evidence of how SMS mobile-phones or internet-based technology can serve to help those even in remote or rural locations $[16,18]$. Radar, mobile and web-based solutions given to policy makers, service providers, and the public can provide timely information dissemination, affordable and effective ways to understand and engage with marginalized o communities [33]. Nowadays, populations which were previously marginalized or particularly remotely vulnerable to infectious diseases and epidemics now have a voice in the global community and access to reliable healthcare advice and resources. These tools can assist in tracking and tracing of some major outbreaks with real time mapping that allows for quicker response, as demonstrated by HealthMap for the Ebola outbreak (http://www.healthmap.org/ en/) and Zika websites [9,10,19,20,34,35]. The HealthMap developed by a team of researchers, epidemiologists, and software designers at Boston Children's Hospital was used to detect Ebola and use for online informal sources, to monitor disease outbreak and real-time surveillance. Maps accuracies were also increased for timely responses, as demonstrated by the Humanitarian Open Street Map Team (HOT) $[9,34,35]$. Organizations such as Medicines Sans Frontiers (MSF), Red Cross, and CartONG work closely with HOT to coordinate mapping and deliver maps to field workers for a detailed and accurate depiction of remote regions (http://hotosm.org). When a major disaster or emergency strikes, the HOT gathers a large network of volunteers to create online maps that allow responds to reach those in need. These maps help workers to better navigate and accurately deliver healthcare in foreign places.

Accuracy and validity may also increase by using technology to transfer health information, as seen with the Health Worker Electronic Response and Outreach (mHero) app, instead of using paper or word of mouth. Electronic delivery of health information via social media, SMS, or mobile apps allows the receiver to identify whether or not the source is valid [35-37]. Though ICTs have increased accuracy, efficiency, validity, and empowerment in some respects there are still numerous ethical issues that emerge from using ICT for Ebola response. Social media could also be the root of a lot of stigmatization, misinformation, misperceptions and fear mongering, to Ebola and Zika complications survivors, frontline bottlenecks and global community late response issues [19]. In October 2014, a Liberian-American woman filmed a video addressing stigmatization of people of African descent due to misinformation about Ebola. The video features a woman with a slogan that says "I am a Liberian, not a virus. She became the first person to start a widespread internet campaign to address Ebola virus infection complication related stigmatization and disability impact on affected families and populations [38].

Implications of digital technologies and applications on emerging threats and epidemics.

Better and timely public communication and engagement strategies are critical to effective outbreak control. ICT and social 
media users to be mindful of the source of the information they refer to information. Governments and organizations can also take steps to better communication by taking simple steps such as getting 'verified' accounts on social media platforms. Creating effective communication strategies will ensure that people get correct, updated, and valid information regarding outbreaks. Reliable and valid information can work to reduce stigmatization, fear, and anxiety among the public. Software developers and tech industry experts should work to ensure safe and secure data sharing. It is difficult to reduce the amount of information overload and 'noise' online as no one can control all mobile and internet dialogue and information dissemination [39-44].

Both prudential, ethics and moral responsibility to actively participate in coordinated global response to public health emergencies wherever they arise requires both justice and prudence in combating the Zika and Ebola devastating outbreaks [4,9]. Recognizing humanitarian obligations and ability of infectious diseases to travel in our interconnected world, ethics and enlightened interest is required to address epidemics at their source. While the Zika and Ebola outbreak has triggered The Bioethics Commission to recommend several targeted policy and research design suggestions, there is currently no policy presented anywhere that directly address the ethical issues that emerge from using ICT during epidemic response [45]. This will tackle the issues of security and privacy that emerge from using ICT as a means of communication during epidemics. Developers of online training modules and tutorials, mobile apps, and SMS should also work to ensure that the trainee gets ethics training on how to treat others during healthcare interventions $[6,11,19]$. For example, asking for consent, or informing a patient that they are being monitored via closed circuit TV demonstrates virtues of patient dignity and respect. There is also debate about the use of drones for humanitarian aid purposes, as they may be confused with military practices and war. In fact, articles and media outlets have frequently referred to Ebola using military imagery deeming it as "The War on Ebola" and describing drones as learning machines [15,29]. Ethics of ICT Use for Ebola epidemic humanitarian aid purposes, community engagement, community consultation, engaging community leaders, and transparency are critical to avoid confusion and miscomprehensions and misconceptions, while building trust and resilience $[1,20,27]$. Ethical use of ICT on Zika and Ebola epidemics response becomes critical and also to discuss the broader implications of using ICT for future emerging epidemics and public health emergencies, communication and effective community involvement, and benefits for healthy lives and wellbeing. During Ebola outbreak, the use of ICT technologies for humanitarian response and awareness and social mobilization and engagement was topical and has ignited much ethical, medical and legal discussions and debates on infectious disease outbreaks that was becoming increasingly common in Zika virus epidemics at the 2014 Technology Salon in Washington, DC, USA (http://technologysalon.org/) [34,35].

Building local early social media, digital maps, and network diagrams are key technologies that have been used to achieve early warning during the Ebola epidemic mapping works to impede public health emergencies and allows individuals to prepare for an outbreak $[8,26,27,46,47]$. Ethics and security in ICT access and use during and post-epidemic public health emergency surveillance and monitoring of formal and informal sources of social media channels such as blog posts and tweets need to be strengthened in most epidemics prone countries $[28,35,36]$. The HealthMap initiative gained much attention since it detected the Ebola outbreak nine days before the WHO formally announced the epidemic similar to Online real-time network diagrams such as the GDELT Project that also used informal online sources to geographically pinpoint where natural disasters or epidemics are occurring far before it was formally announced $[35,36,48]$.

Effective social mobilization empowerment via supportive messaging, short message service (SMS) and Intelligence Voice Response Systems (IVSS) on safety and preventive measures, care seeking treatment and use of protective equipment during safe burial practices and hospital or Ebola centre infection prevention in Sierra Leone and Guinea were used and foster and enhance individual and communities participation and building trust and communities recovery resilience from Ebola outbreak [49]. Access and use of free hotline was also used through IVSS to deliver information regarding Ebola virus prevention strategies. Furthermore, social media was used to educate and inform the public regarding the Ebola 2014 outbreak. Trending hash tags were also popular in parts of Africa during July 2014 to protect and prevent oneself from getting infected $[46,48]$. Similarly, during Zika outbreak, the Centre for Disease and Control (CDC) and WHO-PAHO used social media websites such as Twitter and Flickr to educate healthcare workers on how to protect themselves and how to isolate suspected Ebola or Zika patients' referral systems. WHO- regional centres (AFRO, PAHO, and EMRO) and CDC provided numerous Zika guidelines and update information posters online sharing on social media, via mobile phones, or printed on paper materials on both epidemics. Addressing persistent EVD or ZIKV in semen or blood products or potential break milk in survivors screening and point of care testing coupled with counselling to promote safer sex practices, including reproductive health, condom provision and instructions, and enabled referral for other health problems that survivors might encounter as potential viral reservoirs $[1,3,9,49,50]$. Establishment of continuous of local surveillance program is needed to expand and to provide access and uptake to counselling and psychosocial support to Ebola and ZIKV complications survivors and family, in boosting sexual and reproductive health, increase abstinence and condom use in recovery process. For example in Liberia, men's health screening program represents an important progress toward addressing the challenges in an integrated fashion and opportunity for strengthening health systems that must sufficiently plan rebuilding post-Ebola programs [46,51].

Information sharing for the context of this paper refers to the type of information that is shared between actors involved in the Ebola response. Technologies used most frequently to share information include mobile applications, social media, televideo consulting and SMS services $[3,5]$. For example, a popular application used by frontline health workers is the Health Worker Electronic Response and Outreach app (mHero). mHero was used for the collection of four concurrently running dominant open software systems: DHIS2, RapidPro, Data Coordination Platform (DCP) and iHRIS in contrast to ClinPak in increasing Ebola awareness and communication in Nigeria $[23,24]$. Although, these applications are currently under rapid development, however it has been used during the Ebola outbreak for various tasks, including health worker information coordination, surveillance and reporting, training, real-time human notifications, real-time notifications regarding stock-outs in certain areas, laboratory results reporting and tracking. Social media websites such as Twitter, blog posts, Facebook, and image-sharing websites have been used to deliver messages between actors involved in the Ebola response $[16,18]$. Another example, CDC launched Twitter chat for healthcare workers information sharing and social media SMS responding to the Ebola outbreak. Various other digital tools on frontline SMS-based risk analysis were tested and also help collect and disseminate relevant 
information through mobile phones to frontline humanitarian Red Cross healthcare workers and other stakeholders during West Africa Ebola $[40,41]$

Mapping is one key area for Ebola response as it helps in contact tracing, data-driven decision making, and early warning. Maps help identify population displacement and the spread of the disease so that appropriate interventions can be implemented at the right places, at the right times $[9,15]$. HealthMap has also been used for short term outbreak projections. HealthMap is not the only infectious disease surveillance site. Various other maps have been developed by collecting data from mobile phones [23,24]. Newer technologies that have been used to create maps for the Zika and Ebola outbreak geographical distribution mapping that is a result of data collected from epidemiological, clinical and genomic operational research. HealthMap uses a text processing algorithm to collect data about the spread of Ebola [31,43]. Call Data Record (CDR) maps inform epidemiologists about the location and type of message being delivered, the identity of the caller and the exact location of the person who answered the call to build detailed maps of where people are located, where they are moving to not only inform government about population movement, but shape the nature and location of public health interventions [45,47].

Communicating with those who have come in contact with Ebola can happen via telephone hotlines, video tele-consulting, SMS, social media, or mobile apps. ICTs help healthcare workers collect patient information, as well as allow the patient to contact family and friends. As discussed in previous categories, SMS is used to send public health messages to individuals in West Africa. Hotlines can be called for information where an operator or IVSS answers the call $[29,41,46]$. Furthermore, social media use as a back-and-forth communication channel has been particularly strong for the Ebola outbreak. For example, as of October 2014, 1.3 million tweets regarding Ebola have come out of Liberia, Nigeria, Serra Leone, and Guinea [27,28,29]. Real time video, face-to-screen calls and communication have been used by Ebola patients both in North America as well as West Africa, via secure video calls, a patient in an isolation unit is able to communicate with healthcare workers, family, and friends. Computer programs such as Facebook, Vidyo and VSee allowed high-definition video telemedicine or health information platform during Zika and Ebola outbreaks $[34,36,49,50]$. These various internet and social media methods and applications have been used to train health workers and volunteers to effectively deal with the Zika and Ebola outbreak. SMS-, mobilebased applications, webinars, and online tutorials are used to facilitate patient-providers access, eLearning courses and literacy training, timely information in improving security and performance-oriented multilayers response [46,49-52].

\section{Conclusion}

Coordinated investment on improved digital innovations on threats and epidemics forecasting and rapid response offers a host of potential opportunities and benefits, but also raise significant ethical, legal and medical issues ranging from stigmatization, informed consent, lack of trust, security, privacy, inaccuracy, images of suffering, and inequalities in access and use. The reliance and increased digital access to and use of on data and information storage, sharing and/ or dissemination applications requires better and contextual ethical and medical preparedness for existing and future epidemics potential complications at all levels. Lessons learned and experiences from West Africa Ebola epidemics HealthMap, mobile phone-based applications surveillance and monitoring, other social media and internet emergency education and risk communication response to future Zika and Ebola epidemics prevention and containment. These can serve as foundation for evidence-based local and regional digital public health preparedness and emergency response adoption and implementation to policy makers, governments, the general public, healthcare workers and professionals, and journalists. Fostering evidence-based, comprehensive, cost-effective and real-time frontline digitalization of humanitarian emergencies innovations in strengthening communities' epidemics response and interventions in future epidemics priorities, health systems preparedness and emergency action plans in achieving the 2030 Sustainable Development Goals.

\section{Competing Interests}

Authors declare no conflict of interest.

\section{Authors' Contribution}

ET conceived, gathered all relevant papers and drafted the primary manuscript. ET, AK, MT, CFC and CF provided additional literature review and comments. ET critically revised the whole manuscript. All authors read and approved the final version of the manuscript.

\section{References}

1. Check Hayden E (2016) Spectre of Ebola haunts Zika response. Nature 531: 19

2. Tavernise S (2016) W.H.O. sounds a global alarm over Zika Virus. New York Times.

3. Schuler-Faccini L, Ribeiro EM, Feitosa IML, Horovitz DDG, Cavalcanti DP (2016) Brazilian Medical Genetics Society-Zika Embryopathy Task Force. Possible Association between Zika Virus Infection and Microcephaly-Brazil 65 59-62.

4. Schwind JS, Wolking DJ, Brownstein JS, Mazet JAK, Smith WA (2014) Evaluation of Local Media Surveillance for Improved Disease Recognition and Monitoring in Global Hotspot Regions. PLoS ONE 9: e110236.

5. Strekalova YA (2016) Health Risk Information Engagement and Amplification on Social Media: News about an Emerging Pandemic on Facebook. Health Educ Behav.

6. Gesser-Edelsburg A, Shir-Raz Y, Bar-Lev OS, James JJ, Green MS (2016) Outbreak or Epidemic? How Obama's Language Choice Transformed the Ebola Outbreak Into an Epidemic. Disaster Med Public Health Prep 10: 669-673.

7. Fung IC, Fu KW, Chan CH, Chan BS, Cheung CN, et al. (2016) Social Media's Initial Reaction to Information and Misinformation on Ebola, August: Facts and Rumours. Public Health Rep 131: 461-473.

8. Maduka O, Odia O (2015) Ethical challenges of containing Ebola: the Nigerian experience. J Med Ethics 41: 917-919.

9. Southwell BG, Reynolds BJ, Fowlie K (2013) Communication, media relations and infectious disease surveillance. Infect dis surveil 1: 607-617.

10. Fung IC, Tszhotse Z, Wafu K (2015) The use of social media in public health surveillance. West Pac Surveill Respon J 6: 3-6.

11. Tambo E, Madjou G, Khayeka-Wandabwa C, Tekwu EN, Olalubi OA (2016) Can free open access resources strengthen knowledge-based emerging public health priorities, policies and programs in Africa? F1000Research 5: 853.

12. Weeks BE, Friedenberg LM, Southwell BG, Slater JS (2011) Behavioura consequences of conflict-oriented health news coverage: the 2009 mammography guideline controversy and online information seeking. Health Commun 27: 158-166.

13. Agarwal R (2016) The Public Health Information Technology Maturity Index An Approach to Evaluating the Adoption and Use of Public Health Information Technology. Frontiers in Public Health Services and Systems Research.

14. Fu KW, Liang H, Saroha N, Tse ZT, Ip P, et al. (2016) How people react to Zika virus outbreaks on Twitter? A computational content analysis. Am J Infect Control 44: 1700-1702.

15. Glowacki EM, Lazard AJ, Wilcox GB, Mackert M, Bernhardt JM (2016) 
Citation: Tambo E, Kazienga A, Talla M, Chengho CF, Fotsing C (2017) Digital Technology and Mobile Applications Impact on Zika and Ebola Epidemics Data Sharing and Emergency Response. J Health Med Informat 8: 254. doi: 10.4172/2157-7420.1000254

Identifying the public's concerns and the Centers for Disease Control and Prevention's reactions during a health crisis: An analysis of a Zika live Twitter chat. Am J Infect Control 44: 1709-1711.

16. Dredze M, Broniatowski DA, Hilyard KM (2016) Zika vaccine misconceptions: A social media analysis. Vaccine 34: 3441-3442.

17. Tambo E, Chuisseu DP, Ngogang JY, Khater IM (2016) Deciphering emerging Zika and dengue viral epidemics implications on global maternal-child health burden. J Infect Public Health.

18. Sacks JA, Zehe E, Redick C, Bah A, Cowger K, et al. (2015) Introduction of Mobile Health Tools to support Ebola Surveillance and Contact Tracing in Guinea. Glob Health Sci Pract 3: 646-659.

19. Huff A, Allen T, Whiting K, Breit N, Arnold B (2016) FLIRT-ing with Zika: A Web Application to Predict the Movement of Infected Travelers Validated Against the Current Zika Virus Epidemic. PLoSCurr

20. Voelker R (2016) Miami Obstetrician Uses Evidence to Quell Zika Fears. JAMA 315: 2051-2052

21. Green, E, Hunt, L, Ross, JC (2016) Viraemia and Ebola virus secretion in survivors of Ebola virus disease in Sierra Leone: a cross-sectional cohort study. Lancet Infect Dis.

22. Soka MJ, Choi MJ, Baller A, White S, Rogers E, et al. (2013) Prevention of sexual transmission of Ebola in Liberia through a national semen testing and counselling programme for survivors: an analysis of Ebola virus RNA results and behavioural data. Lancet Glob Health.

23. Southwell BG, Dolina S, Jimenez-Magdaleno K, Squiers LB, Kelly BJ (2016) Zika Virus-Related News Coverage and Online Behavior, United States, Guatemala, and Brazil. Emerg Infect Dis 22: 1320-1321.

24. Almutairi KM, Alodhayani AA, Moussa M, Aboshaiqah AE, Tumala RB, et al. (2016) Ebola outbreak preparedness and preventive measures among healthcare providers in Saudi Arabia. J Infect Dev Ctries 10: 829-836.

25. Liu K, Li L, Jiang T, Chen B, Jiang Z, et al. (2016) Chinese Public Attention to the Outbreak of Ebola in West Africa: Evidence from the Online Big Data Platform. Int J Environ Res Public Healt 13: 780

26. Pigott DM, Millear Al, Earl L, Morozoff C, Han BA (2016) Updates to the zoonotic niche map of Ebola virus disease in Africa. Elife 5: e16412.

27. Trad MA, Jurdak R, Rana R (2015) Guiding Ebola patients to suitable health facilities: an SMS-based approach. F1000Res 4: 43.

28. Tambo E, Khayeka-Wandabwa C, Kamal HA, Khater EIM (2016) Boosting Preparedness and Emergency Response Systems Capacity against Zika and Other Emerging Outbreaks in Low Resource and Vulnerable Settings. Austin J Infect Dis 3: 1018.

29. Snider CJ, Diop OM, Burns CC, Tangermann RH, WassilakSG (2016) Surveillance Systems to Track Progress Toward Polio Eradication-Worldwide 2014-2015. MMWR Morb Mortal Wkly Rep 65: 346-351.

30. Gale TC, Chatterjee A, Mellor NE, Allan RJ (2016) Health Worker Focused Distributed Simulation for Improving Capability of Health Systems in Liberia. Simul Healthc 11: 75-81.

31. Ho SH, Speldewinde P, Cook A (2013) Predicting arboviral disease emergence using Bayesian networks: a case study of dengue virus in Western Australia. Epidemiol Infect 13: 1-13

32. Zhao L, Chen J, Chen F, Wang W, Lu CT, et al. (2015) SimNest: Social Media Nested Epidemic Simulation via Online Semi-supervised Deep Learning. Proc IEEE Int Conf Data Min 1: 639-648.

33. Fung IC, Duke CH, Finch KC, Snook KR, Tseng PL, et al. (2016) Ebola virus disease and social media: A systematic review. Am J Infect Control 44: 1660-1667.

34. Manrique PD, Xu C, Hui PM, Johnson NF (2016) A typical viral dynamics from transport through popular places. Phys Rev E 94: 022304.

35. Yi F, Yang P, Sheng H (2016) Tracing the scientific outputs in the field of Ebola research based on publications in the Web of Science. BMC Res Notes 9: 221
36. Folarin OA, Ehichioya D, Schaffner SF, Winnicki SM, Wohl S, et al. (2016) Ebola Virus Epidemiology and Evolution in Nigeria. J Infect Dis 214: 102-109.

37. Tambo E (2014) Emmanuel Chidiebere Ugwu and Jeane Yonkeu Ngogang Need of surveillance response systems to combat Ebola outbreaks and othe emerging infectious diseases in African countries. Inf Dis Poverty 3: 29

38. Bedrosian SR, Young CE, Smith LA, Cox JD, Manning C (2016) Lessons of Risk Communication and Health Promotion-West Africa and United States. MMWR 65: 68-74.

39. Chapman HJ, Animasahun VJ, Tade AE, Naveed A (2016) Addressing the role of medical students using community mobilization and social media in the Ebola response. Perspect Med Educ 5: 186-190.

40. Capua I (2016) Data sharing: A code of conduct for data on epidemics. Nature 534: 326.

41. Hadi TA, Fleshler K (2016) Integrating Social Media Monitoring Into Public Health Emergency Response Operations. Disaster Med Public Health Prep 27: 1-6.

42. Adebimpe WO, Adeyemi DH, Faremi A, Ojo JO, Efuntoye AE (2015) The relevance of the social networking media in Ebola virus disease prevention and control in Southwestern Nigeria. Pan Afr Med J 22: 7.

43. Castellanos JE (2016) Zika: a defeat in the struggle against Aedes aegypti. Biomedica 36: 5-9.

44. Gornet ME, Bracero NJ, Segars JH (2016) Zika Virus in Semen: What We Know and What We Need to Know. Semin Reprod Med 34: 285-292.

45. Colf LA, Brothers R, Murata CE (2016) A Role for Science in Responding to Health Crises. Health Secur 14: 272-279.

46. Tambo E, Chengho CF, Ugwu CE, Wurie I, Johnson JK, et al. (2017) Rebuilding transformation approaches and strategies in post-West Africa Ebola epidemic Infec Dis Pov 6: 3-7.

47. Achrekar H, Gandhe A, Lazarus R, Yu SH, Liu B (2013) Biomedical Engineering Systems and Technologies. Springer Online Social Networks Flu Trend Tracker: A Novel Sensory Approach to Predict Flu Trends 1: 353-368.

48. Otu A, Ebenso B, Okuzu O, Osifo-Dawodu E (2016) Using a mHealth tutoria application to change knowledge and attitude of frontline health workers to Ebola virus disease in Nigeria: a before-and-after study. Hum Resour Health 14: 5 .

49. http://apps.who.int/iris/bitstream/10665/250626/1/WHO-ZIKV-SRF-16.4-eng pdfhttp://apps.who.int/iris/bitstream/10665/250626/1/WHO-ZIKV-SRF-16.4 eng.pdf $\% 20$

50. Sharma M, Yadav K, Yadav N, Ferdinand KC (2017) Zika virus pandemicanalysis of Facebook as a social media health information platform. Am J Infect Control 45: 301-302.

51. Lehnert JD, Ellingson MK, Goryoka GW, Kasturi R, Maier E, et al. (2017) Use of Obstetric Practice Web Sites to Distribute Zika Virus Information to Pregnant Women During a Zika Virus Outbreak. J Public Health Manag Pract.

52. McGough SF, Brownstein JS, Hawkins JB, Santillana M (2017) Forecasting Zika Incidence in the 2016 Latin America Outbreak Combining Traditional Disease Surveillance with Search, Social Media, and News Report Data. PLoS Negl Trop Dis 11: e0005295 